\section{Empresarios, señoritas y obreras. Las escuelas de fábrica para obreras de la Liga Patriótica Argentina (1920-1928): ¿Una experiencia exitosa?*}

(4) Ludmila Scheinkman***

\section{Resumen}

Este trabajo se propone reconstruir el desarrollo de las escuelas de fábrica de la Liga Patriótica Argentina, radicadas en grandes centros de empleo femenino de la Ciudad de Buenos Aires en la década de 1920, ya que son una lente interesante para explorar las problemáticas de género en el mundo laboral. Aunque considerable literatura aborda el desarrollo de la Liga, en su mayoría se ha concentrado en los aspectos represivos de la misma, omitiendo las dimensiones del género y la sexualidad. Sin embargo, una de las actividades centrales de la organización para obtener el adoctrinamiento y la pacificación de la clase obrera fue el establecimiento de escuelas fabriles para mujeres. Este trabajo busca reconstruir esta experiencia pedagógica, parte fundamental de la actividad de la Liga, y ponderar los alcances de este "éxito" pedagógico y político, sus causas y posibles efectos para pensar la problemática de la sindicalización y las dificultades de las izquierdas para insertarse en grandes concentraciones fabriles con importante presencia de empleo femenino en 1920. Para ello, trabajaremos con las Memorias de las Escuelas para Obreras, con publicaciones oficiales de la organización y prensa periódica.

\footnotetext{
Abstract

This paper intends to reconstruct the development of factory schools founded by the Argentine Patriotic League, located in major centers of female employment in the city of Buenos Aires in the 1920s, as they are an interesting lens to explore gender issues in the workplaces. While there is considerable literature addressing the development
}

*Fecha de recepción: 25 de julio de 2015. Fecha de aceptación: junio de 2016

\section{Palabras clave:}

Liga Patriótica Argentina; Derechas; trabajadoras; educación.

\section{Keywords:}

Argentine Patriotic League; Right-Wing movements; female labor; education. 
1 McGee Deutsch (2003:162) registra la existencia de las escuelas hasta la década de 1950, pero abarcaremos en el trabajo hasta 1928, último año para el que disponemos memorias. of the League, most of it has focused on its repressive aspects, omitting the dimensions of gender and sexuality. However, one of the main activities undertaken by the organization for indoctrination and pacification of the working classes was the establishment of factory schools for women. This paper aims to reconstruct this educational experience, as a fundamental part of the League's activity. And ponder the implications, causes and possible effects of this pedagogical and political "success", in order to rethink the difficulties of unionization and left-wing organizations' insertion in large manufacturing concentrations of female employment in the 1920s. In order to do this, we work with the schools' Memories, the organization's official publications and newspapers.

La obrera Auria Pérez debía sentirse nerviosa la mañana del 18 de diciembre de 1926. Mientras se aseaba puntillosamente según lo aprendido en sus clases de Anatomía y Moral, escogía sus mejores ropas, probablemente de su confección, para vestirse con pulcritud. Había sido elegida por sus compañeras de trabajo y estudio y sus maestras para pronunciar el discurso de agradecimiento en la entrega anual de premios de la escuela para obreras de su fábrica, ante las distinguidas benefactoras de la Comisión Central de Señoritas (CCS) y los señores de la junta central de gobierno de la Liga Patriótica Argentina (LPA). Además, asistirían algunos miembros del directorio y gerencia de la gran fábrica de galletitas y licores Bagley y no menos de 400 de sus compañeros y compañeras de la fábrica, sentados prolijamente para escucharla: a un lado del salón las obreras; del otro los obreros. Luego del Himno Nacional, todos los ojos estarían puestos en ella. Debía pronunciarse bien y hablar con claridad, como le habían enseñado en sus lecciones de Escritura y Lenguaje. Tal vez su buen desempeño le valiera el ascenso a un puesto de taquigrafía, lejos de las líneas de montaje (LPA y CCS, 1926-1927; 1927: 18-19). Las ansiedades y expectativas de Auria Pérez probablemente fueran compartidas por muchas de sus compañeras. El primer curso para obreras se había establecido en Bagley en 1920 con solo 15 de las 500 obreras de la fábrica (LPA y CCS, 1924-1925; 1925: 4) En mayo de 1928 Celina de Estrada, presidenta de la CCS y pariente de José Manuel de Estrada, informaba que habían pasado 9.097 alumnas de distintas nacionalidades por las ahora 12 escuelas que sostenía la LPA en distintas fábricas, "prueba evidente de la confianza que estas han despertado entre el elemento obrero" (LPA y CCS, 1927-1928; 1928:5).

Este trabajo se propone reconstruir el desarrollo, entre 1920 y $1928,{ }^{1}$ de las Escuelas de Fábrica de la LPA, instaladas en grandes focos de empleo femenino de la Ciudad de Buenos Aires, ya que son un lente interesante para explorar las problemáticas de género en el mundo laboral. La considerable literatura que estudió a la LPA se ha concentrado en sus aspectos represivos (Godio, 1972; Rock, 1977; Bilsky, 1984; Ospital, 1994; Caterina, 1995; Lvovich, 2003), pero incluso antes de la derrota de las huelgas, otra actividad central de la LPA para el adoctrinamiento y la pacificación de la clase obrera fue el establecimiento de escuelas fabriles para obreras. Aunque el mismo Manuel Carlés, presidente de la LPA, señaló que las escuelas eran parte fundamental de su proyecto (McGee Deutsch, 2003: 164), esta experiencia pedagógica no ha recibido un análisis acorde. Sandra McGee Deutsch, que ha analizado las problemáticas de género, estudió a las mujeres de la LPA pero no se ha focalizado en la acción de estas sobre las obreras (McGee 2003; 2005).

La creación de instituciones educativas es una intervención "clásica" de los programas industriales "paternalistas" orientados a incidir en los tiempos extralaborales de obreras y obreros para disciplinarlos. Extensa literatura sobre el empresariado en Argentina ha estudiado experiencias exitosas de paternalismo, e incluso "villas obreras" (Barbero y Ceva, 1997; Ceva, 2010; Lupano, 2009; Neiburg, 1988; Rocchi, 2000a), algunas con fuerte contenido religioso impulsadas por militantes católicos (como Steverlynck en Algodonera Flandria o Benedit en la Fábrica Nacional de Calzado). 
Otros trabajos han abordado la aplicación de "prácticas de tipo paternalistas", señalando sus alcances y límites e incluso, su inexistencia en algunas gestiones empresariales (Badaloni, 2007; Caruso, 2012; Dicósimo, 2008; Lobato, 2001; Simonassi, 2007), recuperando también la agencia obrera.

Este trabajo estudia una práctica paternalista no emprendida directamente por los patrones -si bien contó con su apoyo-, e indaga también en las respuestas obreras. Además, pretende ponderar los alcances de este "éxito" pedagógico y político, y sus posibles efectos para pensar la sindicalización y la inserción de las izquierdas en grandes concentraciones de empleo femenino en 1920. Para ello, trabajamos con las Memorias de las Escuelas producidas por la CCS. Aunque pretendían ser anuales, sólo se han conservado cuatro (1922: 22; 1925: 51; 1927: 72 y 1928: 54). De pequeño formato, su tono era elogioso y autoproclamatorio, y buscaban ensalzar el éxito de su obra patriótica frente a los miembros masculinos de la LPA, la Comisión Central de Señoras de la LPA, y los gerentes y patrones de las fábricas en las que actuaban o buscaban actuar. Allí mencionaban el éxito y los beneficios de la obra de la CCS, el desenvolvimiento de las escuelas, descripciones de las actividades realizadas, la cooperación de las fábricas, transcripciones de discursos de Carlés, de autoridades de la CCS y de obreras destacadas en las entregas de premios y actos anuales de cierre de cursos, ilustradas con fotografías de obreras y autoridades. Ocasionalmente incluyeron programas de estudio y reglamentos. Estas se complementan con otras publicaciones oficiales de la LPA y prensa periódica de la época.

\section{La Liga Patriótica y la división sexual del trabajo: "mujeres útiles a la Patria"}

Entre 1918 y 1922 -los años críticos de la primera posguerra y la oleada global de huelgas tras la Revolución Rusa-, la Argentina registró altísimos índices de conflictividad detonados por la depresión económica y los efectos de la inflación sobre los salarios reales (Rock, 1977: 139). En este clima de "miedo rojo" y extrema agitación social surgieron organizaciones contrarrevolucionarias de derecha como la Asociación del Trabajo ${ }^{2}$ y la LPA para enfrentar el ímpetu izquierdista que, en su evaluación, el gobierno radical de Hipólito Yrigoyen no quería o no podía frenar. Formada a partir de grupos civiles y parapoliciales, miembros de la "aristocracia" local, militares, policías en activo o retirados, prelados, políticos conservadores y radicales, que actuaron en la "protección" de los barrios durante la Semana Trágica de 1919, el eje del accionar de la LPA durante los años álgidos de conflictos fue reprimir las huelgas y al movimiento obrero. Sin embargo, sus objetivos y acciones eran más amplios: la defensa de la nación, la unidad del pueblo, el amor por las fuerzas armadas y las instituciones, estimular sentimiento de argentinidad y la defensa del hogar. Para naturalizar e incorporar a los inmigrantes a la vida nacional, y neutralizar la difusión de “ideologías foráneas", era fundamental la labor educativa y pedagógica (LPA, 1919).

Esta fue emprendida por las integrantes femeninas de la LPA, de acuerdo con una "división sexual del trabajo" al interior de la organización, que reproducía y reforzaba los roles tradicionales de género, pero a la vez colocaba a las mujeres en un lugar de inédito papel político, no exento de tensiones (McGee Deutsch, 2003: 158). Como señalaba Carlés en un cierre de cursos "nos reservamos nosotros el empeño de limpiar la calle manchada por el exotismo inmoral [...] (y las) Señoritas se impusieron el deber sagrado de enseñar la verdad y el bien en escuelas cuyo éxito patentiza esta fiesta" (Carlés, 1921:3-4), una misión fundamental. Fue precisamente un rasgo saliente de la Liga, a instancias de su presidente y en sintonía con experiencias previas del catolicismo social, ${ }^{3}$ el interés por el reclutamiento femenino y la alta valoración de

2 Surgida para la defensa del "trabajo libre" en las huelgas (Rapalo 2012, 58 ) mantuvo estrechos vínculos con la LPA. 
4 Carlés colocaba a las ilustres Señoritas de la CCS a la altura del panteón (femenino) de la gesta de

Mayo, las llamaba "próceres de la gloria contemporánea" y las equiparaba a "hombres" de Estado. la contribución patriótica que "las santas mujeres de la República que enseñan la verdadera civilización argentina, fundada en la familia, en la patria, en Dios" (LPA y CCS, 1924-1925; 1925: 17) tenían para dar. La tarea que se les encomendaba era elevada, noble y crucial: la educación moral, religiosa y patriótica de las obreras para evitar el conflicto de clases disolvente de la Nación. No sorprende, por lo tanto, que mujeres de la alta sociedad adhirieran masivamente a la Liga, donde su accionar era valorado y podía rendir frutos significativos.

Esto llamó particularmente la atención de sus adversarios, que consideraban que la incorporación femenina era una respuesta al fracaso en el reclutamiento masculino. Los anarquistas de La Protesta, que concebían a las mujeres de la "aristocracia local" como "tolerantes y complacientes (...) ignorantes de todo y con una mentalidad estrecha muy inferior", consideraban en 1919 que como "sólo las 'damas' constituyen ahora su principal fuerza militante", la LPA estaba "llamada a desaparecer en un breve plazo" (N.N, 1919)Este pronóstico se mostró errado en tanto la Liga continuó funcionando activamente durante toda la década de 1920. Pero, el diario percibía como defecto, aquello que era precisamente una fortaleza de la Liga: la militancia femenina. Los liguistas se empeñaron y tuvieron cierto éxito en reclutar aquello que los anarquistas parecían juzgar de "segundo orden". Las obreras, más distantes de la prédica anarquista, parecían algo más receptivas al llamado conciliatorio de la Liga. A través de ellas , Carlés esperaba incidir en la familia obrera y neutralizar el activismo fabril, y no dudó en equiparar el éxito y la viabilidad de la LPA con el de las escuelas de fábrica (LPA y CCS, 1924-1925; 1925: 16). La escuela patriótica "enseña a la obrera a ser hija, esposa y madre ejemplar; como hija, ayuda y alegría del hogar; como esposa, confidente, consejera y amante del marido; como madre, sentir el hogar, ser sostén y columna del marido, inspirar patriotismo en el ambiente." (LPA y CCS, 1926-1927; 1927: 42) . La defensa de la familia y el hogar eran cruciales para mantener el orden social burgués. En este punto, Carlés permanecía apegado al liberalismo decimonónico por cuanto consideraba que, con fuertes dosis de patriotismo inculcadas por la educación, la Liga resolvería la cuestión social, considerada un dilema más moral que económico (Devoto, 2002: 75). De todos modos, la acción pedagógica de la LPA sobre las mujeres obreras fue un antecedente temprano, aún no reconocido por la historiografía, del creciente interés del nacionalismo y el catolicismo social en 1930 por actuar sobre los trabajadores (Rubinzal, 2012).

\section{Las escuelas para obreras de la Liga Patriótica Argentina}

Las escuelas de la Liga se orientaron a la educación de las obreras. Excepcionalmente hubo cursos de varones, pero no fue esta la regla ni su espíritu. Por ello se instalaron en algunas de las más grandes e importantes fábricas alimenticias, textiles, de confección, cigarrillos y químicas de la ciudad que empleaban gran cantidad de mujeres: Bagley, Bunge y Born (bolsas de arpillera), Alpargatas (textil), Piccardo (cigarrillos), Noel (dulces), Farmaco Argentina (química) y Gratry (textil), entre otras. ${ }^{5}$ La primera escuela se organizó en Bagley con la colaboración de la gerencia en 1920. La escasa inscripción se explicaba porque el "apostolado de concordia social" de las Señoritas se había iniciado en un contexto adverso en que "imperaba la intransigencia más hostil en las asociaciones obreras contra todo lo argentino que tuviera relación obrera o no estuviese consentido por sus gremios y sindicatos" (Carlés et al., 1922: 1). Tras las 8 horas de labor, "los obreros escapaban precipitadamente de los talleres como si huyeran de un presidio. No así las obreras, para quienes no era programa atrayente la calle con los peligros de la galantería malsana, ni la tarde en el conventillo con la incomodidad de su hacinamiento. Para matar las horas hasta pensaron las pobres obreras concurrir a las academias de tango" (pp. 1-3). Las Señoritas iniciaron entonces, 
fundando escuelas, una ardua batalla por el control del tiempo libre de las obreras, pese a la hostilidad de sindicatos y gremios. Juzgaban que la jornada de ocho horas se aplicaba con "demasiada" rigidez, dejando "excesivas" horas libres a las trabajadoras, y las actividades de las jóvenes en su tiempo "ocioso" eran preocupantes por los peligros que acechaban: a las influencias de activistas gremiales y políticos, se sumaban diversiones de perniciosos efectos morales.

La acción liguista se apoyaba sobre distintas concepciones y evaluaciones morales de los varones y mujeres de la clase trabajadora. Los primeros eran estigmatizados como vagos: huían del trabajo terminada la jornada, hacia las calles, los vicios, el anarquismo y el socialismo. Considerados irrecuperables, no hubo una política sistemática hacia ellos. Las obreras en cambio se aplicaban al trabajo, y era el aburrimiento y la ingenuidad lo que podía volcarlas a los peligros morales y físicos de las calles, al hacinamiento inmoral de los conventillos o las peligrosas tanguerías. Eran consideradas recuperables y maleables la acción abnegada de las jóvenes patriotas de la alta sociedad se orientó hacia ellasorganizando escuelas. Pero "la concordia y los buenos modales" que aconsejaban las Señoritas de la Liga Patriótica fueron resistidos en ese mundo atemorizado por los "agitadores":

A pesar de los peligros que ciertamente suponía esperar a las obreras en los portones de las fábricas, es decir, mezclarse con los adversarios, las buenas Señoritas presididas por Celina de Estrada, pacientes, con valor y sonrisas supieron cautivar a las obreras para conseguir su amistad y que les tuviesen confianza. De este modo, las Señoritas conocieron el desabrimiento que producía en los talleres femeninos el horario de las ocho horas y el afán que todas tenían por encontrar ocupación a la novena hora de la jornada. [...] Las Señoritas obreras y las Señoritas de la Liga Patriótica, cuyo trato frecuente y amable concluyó por vincularlas con la buena voluntad de las almas sinceras, encontraron la manera de resolver la dificultad del horario. iEstablezcamos escuelas, se dijeron! [...] La casi totalidad de las obreras son analfabetas. Se abochornan confesar que no saben leer. Agregada la propaganda de los hostiles a la Liga Patriótica, se comprende que la concurrencia escolar fuera escasa en las aulas de las primeras escuelas de las nobles Señoritas. Pronto, sin embargo, las escuelas se difundieron en todos los barrios de la metrópoli. A medida que se evidenciaba el éxito de la enseñanza, que las obreras más recalcitrantes veían con la facilidad que se aprendía a leer en la escuela, todos, al fin, los obreros y obreras de la fábrica concurrieron (Carlés, LPA y CCS, 1922: 1-3).

Este relato fundacional resaltaba la "militancia", tenacidad y convencimiento de las Señoritas que se habían abierto paso entre las obreras frente a la inicial intransigencia y resistencia de "adversarios", los obreros varones sindicalizados, en un contexto hostil y riesgoso. La derrota parcial del movimiento obrero había posibilitado el avance de las liguistas, que con su dulzura y modales cautivaron a las obreras, receptivas a su prédica de "buena voluntad". Según el relato, para las trabajadoras fabriles (e incluso para algunos obreros) la gran atracción de las escuelas era la posibilidad de alfabetizarse y adquirir conocimientos básicos "con facilidad", puesto mayormente eran analfabetas. Gracias al tesón de las Señoritas en los primeros años, y a la utilidad práctica de las escuelas, se había logrado multiplicarlas, "resolviendo" el problema del tiempo libre de las trabajadoras.

Pese a su discontinuidad, los números consignados en las memorias permiten reconstruir un panorama del crecimiento de las escuelas. En 1922 la memoria informaba de quince establecimientos funcionando, aunque luego solo mencionaba cinco: Bagley mujeres y varones, Gratry, Mitau y Grether, Avanti y Pratt (p. 13)..En 1925, según la memoria funcionaban diez escuelas, que "llegarán a veinte en el transcurso de este 
año". Sin embargo, solo detallaba ocho: Bagley mujeres y varones, Gratry, Mitau y Grether, Avanti, Patricios (Alpargatas), Dell Acqua, Bunge y Born y Adot. Entre 1926 y 19277 habían funcionado trece escuelas, y en 1928, doce: Bagley mujeres y varones, Mitau y Grether, Avanti, Patricios (Alpargatas), Bunge y Born, 43 (Piccardo), Muñoz Sauca, Algodonera Argentina, Farmaco Argentina, Noel y Campomar y Soulas. La discrepancia en los números consignados puede deberse a que en las restantes fábricas no había verdaderas escuelas, sino un pequeño curso de alfabetización. Sin embargo, en 1928 la cantidad de escuelas se había duplicado respecto de las cinco de 1922. Este claro crecimiento no fue tan espectacular como nos querían hacer creer las memorias: hubo una fluctuación en la cantidad de escuelas, y algunas como Pratt, Dell'Acqua o Adot desaparecieron de las memorias, lo que indica su declive o cierre.

En 1922 el promedio diario de asistentes era de 2.500 y la media de asistencia mensual era de 5.000 obreros y obreras, "casi todos analfabetos"; un 80 por ciento había aprendido a leer y escribir gracias a la acción pedagógica liguista (LPA y CCS, 1922: 42). En 1924 se inscribieron 1.600 alumnas, registrándose 68.700 asistencias anuales (LPA y CCS, 1924-1925; 1925:3). Promediando las asistencias por la cantidad de alumnas, se deduce que la alumna tipo asistía a poco menos de una clase por semana. En algunas grandes fábricas que contaban con decidido apoyo de las patronales, como Bagley, Alpargatas, o Piccardo (cigarrillos), funcionaban verdaderas escuelas, en las se impartía un currícul educativo completo. Pero en la mayoría de las fábricas, como Adot, Muñoz Sauca (medias), Algodonera Argentina (textil), Farmaco Argentina o Noel, había tan solo un curso básico semanal de primeras letras y costura simple que funcionaban con una maestra.

Todos los años los dueños de las fábricas daban licencia a las alumnas para asistir a los desfiles y actos organizados por la LPA para festejar las fiestas Mayas y Julias. Las alumnas cantaban el himno, interpretaban números y recitaciones, y las Señoritas repartían escarapelas, masas y caramelos. Realizaban también exposiciones y ventas de labores y en Navidad repartos de juguetes "para los hijos y hermanitos de las obreras" (LPA y CCS, 1924-1925; 1925: 35). Para la "protección" de las trabajadoras se entregaban camas en hospitales, anteojos, tónicos, remedios y pasajes. Entre los logros se consignaban las comuniones, bautismos y casamientos religiosos concretados (LPA y CCS, 1924-1925; 1925: 38). En todas las grandes escuelas se realizaba una distribución anual de premios donde se exponían las labores y cuadernos de caligrafía y aritmética de las alumnas, que realizaban recitados, canto, música y "cuadros vivos". Carlés presidía la ceremonia con palabras aleccionadoras y una obrera destacada daba el discurso de agradecimiento frente a directivos, gerentes y autoridades de la CCS y la LPA.

La cooperación de las fábricas fue fundamental para la instalación y el sostenimiento de estos emprendimientos. Esta se plasmó en el espacio cedido para aulas y en numerosas donaciones: bancos, libros, premios, banderas, caramelos, lápices y por supuesto, grandes sumas de dinero. Las Señoritas realizaban también, para recaudar fondos, actividades variadas como rifas, fiestas y tés a beneficios. Además, los señores de la Junta Central de Gobierno lograron instalar alcancías para donaciones en varios bancos y comercios. De este modo, las escuelas eran cofinanciadas por la LPA y las gerencias de las fábricas. Muchas de estas industrias formaban parte de la Asociación del Trabajo, que tenía ceñidos vínculos con la LPA (Caterina, 1995: 95); de allí el trato fluido entre la LPA y empresarios. Según las memorias, incluso algunas fábricas solicitaban a la LPA la apertura de escuelas (LPA y CCS, 1922: 6).

En 1925 se aprobó un programa de enseñanza y un reglamento interno con los horarios y deberes de directoras, maestras y alumnas, que codificaba la experiencia de 5 años de trabajo. Podían concurrir todas las obreras de las fábricas sin distinción 
de nacionalidad (el objetivo era precisamente "argentinizarlas"), desde los 14 hasta los 60 años, de acuerdo a la legislación de 1924 sobre trabajo femenino e infantil. Las clases se dictaban entre las 5 y 7 p.m., tras el cierre de las fábricas, concluido el trabajo diario. El objetivo era no interferir con la jornada laboral, que de acuerdo a la Ley 11.317 (1924) era de 8 horas para las mayores de 18 años, y 6 para las menores. La enseñanza y los útiles eran gratuitos.

Las directoras debían ser puntuales y vigilar la asistencia, puntualidad, preparación y aptitudes de las maestras y debían comunicar a la Presidenta de la CCS cualquier negligencia. Llevaban el registro de matrícula, la asistencia diaria, establecían el horario, hacían cumplir el programa, elevaban informes mensuales y distribuían el trabajo. Debían comunicar a la Presidenta los pedidos de las alumnas (recomendaciones laborales, anteojos o remedios) y no podían tomar determinaciones ni iniciativas, ni hacer pedidos a las fábricas sin antes consultar con la Presidenta. A fin de curso, seleccionaban a las alumnas premiadas e informaban las Comuniones realizadas. $\mathrm{Si}$ bien debían cooperar con la LPA en la enseñanza nacionalista, no eran necesariamente integrantes de la Liga, sino contratadas.

Las maestras también debían ser puntuales y cumplir su horario, colgado a la vista para control. Llevaban un libro de tópicos diarios, un cuaderno de ejercicios y planes de clases, entregados mensualmente a la Presidenta para su revisión. Debían secundar a la directora velando por la disciplina y moral de las alumnas, fomentando el "buen gusto" y el ahorro. No podían tomar decisiones sin consultar a la directora, pero debían tener iniciativas e ideas propias que pudieran favorecer a las escuelas. Debían predicar con la palabra y el ejemplo "enseñando con cariño y reprendiendo con bondad" (LPA y CCS, 1924-1925; 1925: .48-50). Era tarea suya también inculcar en el "alma" de las alumnas sentimientos de amor a Dios, a la Patria y a la familia.

Como se aprecia, se trataba de una estructura de mando jerárquica y vertical, donde el cumplimiento de las órdenes era estrictamente vigilado por los escalafones superiores. A su vez, la puntualidad y el horario debían ser estrictos, así como el control, la vigilancia y la obediencia. En el escalón más bajo se encontraban las alumnas, cuyos deberes y disciplina "inquebrantable" se detallaban: asistencia regular y puntualidad; aseo "perfecto" en la persona, el vestir y los útiles; el "deber inexcusable" de ser respetuosas y obedientes con sus maestras, tolerantes con sus compañeras y "dignas" en todo momento; velar por el nombre y prestigio de la escuela dentro y fuera del aula y conservar los muebles, útiles, etc. Por último, debían amar, honrar y servir a Dios y a la Patria (LPA y CCS, 1924-1925; 1925: 50). Como se ve, la obediencia, la sumisión, la puntualidad, el respeto, y las actitudes y valores que se buscaba inculcar a las obreras eran totalmente funcionales a la disciplina fabril. El objetivo de este programa era enseñar "el verdadero principio de la filosofía del trabajo": la colaboración y conciliación de clases. Decía Carlés: "Aquí las obreras aprenderán que la República es la concordancia de todas las voluntades y la solidaridad de todos los esfuerzos en la producción [...]. Se enseñará al obrero a defender al patrón, y el patrón aprende a defender al obrero, para que al buen obrero corresponda el buen patrón" (LPA y CCS, 1924-1925; 1925: 18).

El programa de enseñanza plasmaba la línea ideológica de la LPA. Su objetivo no era la formación en oficios o conocimientos útiles al trabajo fabril, sino que los contenidos estaban supeditados a una finalidad política. Incluso en alfabetización y cálculo, desarrollados en Aritmética, Geometría, Lectura y Escritura y Lenguaje, se incluían temas significativos a la vida laboral como "Conversaciones sobre las diversas ocupaciones que constituyen sus medios de vida", "Conversación sobre la procedencia y transformación que sufre la materia prima en su trabajo", "Herramientas y útiles empleados en las distintas tareas" y "Narración oral y escrita sobre el trabajo constante y silencioso" 
(LPA y CCS, 1924-1925; 1925: 44). Hasta las asignaturas básicas pretendían inculcar la aceptación resignada y "silenciosa" de las condiciones de vida, la obediencia y la disciplina en el trabajo "constante". En Historia y Geografía argentinas, y "Deberes con la Patria", se impartían los aspectos patrióticos y de nacionalización: se enseñaba a obedecer y cumplir con las obligaciones legales, tributarias y religiosas. La definición de Patria para la Liga estaba indisolublemente ligada a la religión. No sorprende que el eje estuviera puesto en los deberes y no en los derechos.

Los motivos higienistas y disciplinares, el refuerzo del rol doméstico de la mujer y la construcción de la feminidad se transmitían en materias como Anatomía (cuerpo humano, aseo corporal, limpieza, etc.). En Moral se enseñaban los deberes con respecto al cuerpo y al alma y valores como el trabajo (frente a la ociosidad y la pereza), la paciencia, la modestia exterior e interior, deberes con los padres, hermanos y maestros, respeto, obediencia, amor, gratitud, caridad, asistencia y aplicación. Nuevamente el cumplimiento de los deberes, las obligaciones y la sumisión estaban en primer plano. En Urbanidad se explicaban las leyes en el hogar, la escuela, la sociedad, la mesa, la calle y el templo, y la "alegría" y sus efectos en la sociedad, la familia y el trabajo. Por último, se enseñaba que "el contento es la mejor forma de la cultura", inculcando el conformismo y desestimulando las luchas por derechos o mejoras en las condiciones de vida. Las materias de Labores, Puericultura, Primeros Auxilios, Catequesis y Costura enseñaban a la mujer a ser madre, a cuidar a sus hijos, a confeccionar la ropa de la familia; en otras palabras, a ser mujeres domésticas.

Este proyecto y programa escolar se apoyaba en una concepción de las mujeres como "moderadas" y moldeables, por lo tanto, receptivas al evangelio de la Liga. Ésta buscaba por su intermedio, reforzar la responsabilidad en el trabajo y el hogar y mantener a las mujeres lejos de las calles. Aunque las escuelas se orientaron a obreras, la educación impartida les enseñaba a ser madres, hijas, esposas, y guardianas del hogar; es decir, a ser "mujeres". Los contenidos no estaban pensados para ayudarlas a prosperar en sus propios trabajos, en tanto el empleo femenino fabril fue entendido en la época como una "excepción" transitoria a la norma doméstica, "complementario" al empleo masculino (Lobato, 2007; Queirolo, 2010).

Una excepción que ilustra este punto son los cursos de dactilografía inaugurados en algunas escuelas al promediar la década. Estos fueron abiertos a instancia y pedido de las obreras, ya que las habilitaban y formaban para el trabajo "de escritorio". Graciela Queirolo (2008) ha mostrado que en los empleos administrativos en expansión en la década de 1920 se podía obtener salarios más altos y trabajos mejor remunerados que poseían prestigio simbólico. Para acceder a puestos como el de dactilógrafa eran requisitos la destreza en la mecanografía y el conocimiento profundo del idioma español. Algunas fábricas adoptaron la política de promoción de las mejores alumnas de las escuelas, estimulando la diferenciación entre las obreras y las expectativas de ascensos, restringidas de todos modos a una minoría. En 1927, cinco obreras pasaron a puestos de escritorio en Alpargatas, y otras cuatro a escribir a máquina en la "Sección Propaganda" de Bagley (LPA y CCS, 1927; 1928: 43-44). De hecho, Fernando Rocchi considera, a partir de las opiniones vertidas por la patronal de Bagley en los Libros de Actas del Directorio, que una de las claves del éxito de la escuela fue que hacia 1927 los cursos de cocina y labores habían sido desplazados por otros relacionados con los trabajos de oficina, que implicaban la posibilidad de convertirse en empleadas (Rocchi, 200ob: 238).

Sin embargo, estos cursos fueron excepcionales y tardíos en el desarrollo de las escuelas y en la mayoría de las clases se reforzaba el rol femenino del aseo, la limpieza, el vestido de la familia y el cuidado del hogar. Resulta paradójico que se pretendiera que estas mujeres, encerradas de seis a ocho horas en las fábricas y luego en la escuela, 
tuvieran tiempo de cumplir con mandatos y tareas que redundaban en reforzar la doble jornada laboral y doméstica. Además, como muchas obreras vivían hacinadas en conventillos (LPA y CCS, 1922:1), las posibilidades reales de concretar el "hogar ideal" eran más bien escasas.

Los valores que impartían los cursos eran ante todo útiles a los patrones, por eso, estos prestaron su apoyo material y patrocinaron las escuelas. Aunque el patrocinio fue desigual, la mayoría contribuyó de algún modo. sin embargo, algunos casos como Alpargatas, Mitau y Grether, Bunge y Born, Piccardo o Bagley (que incluso construyó aulas) dieron año a año el apoyo más firme, y en esas fábricas las escuelas lograron afianzarse. En cambio, otras como Pratt, Campomar y Soulas o Algodonera Argentina se limitaron tan solo a "ceder" locales; en ellas, las escuelas no fueron tan fuertes. Algunos patrones sin dudas juzgaban beneficiosa la creación de escuelas, e incluso fábricas como Saint Hnos. instalaron escuelas fabriles para obreras por su cuenta mucho antes (N.N, 1922:227-228). Pero cabe preguntarse si la obsesión de la LPA por el patriotismo no sonaba un tanto ajena en una sociedad de inmigración. Es probable que en algunos casos los patrones solo "cedieran" ante las insistentes Señoritas de la alta sociedad porteña, que movilizaban contactos, influencias y dinero a su favor.

Al mismo tiempo, adoctrinando a la mujer, el elemento más "dócil" y "moldeable" de la familia obrera, la Liga esperaba cumplir sus propios objetivos, tales como la nacionalización de las extranjeras, la difusión del espíritu patriótico y la conciliación de clases en la fábrica y el hogar, contribuyendo de este modo a mantener el orden. Frente a la "avalancha del odio de clase importado", la LPA opuso sus ideales de humanitarismo, civilidad, moral y patriotismo. Los objetivos de las escuelas eran claros: nacionalización, maternalización, defensa de la familia, conciliación de clases, neutralización del movimiento obrero, mantenimiento del orden y del statu quo; también los medios para conseguirlos: cursos y materias, programas de enseñanza, actividades, disciplina, labores, concursos, premios y actos patrióticos. Carlés lo sintetizaba: "Las escuelas de la LPA han formado las heroínas de la Nación" (Carlés, 1921: 7-8). Ahora bien, ¿adhirieron las obreras a este programa? ¿Fueron receptoras pasivas de la línea doctrinaria de la LPA? En suma, ¿fueron realmente un éxito las escuelas?

\section{La adhesión de las obreras: ¿un éxito contundente?}

"Soy la galletita Lola/ de gran popularidad/ deliciosa en aroma/ ricas al buen paladar/ por no hacerlos desear/ empezaré con primor/ siendo yo la reina de todas/ les presentaré el AMOR/ ¿Saben lo que es el amor? / las galletitas más finas/ que de la Industria Argentina/ hoy se puede conocer" (LPA y CCS, 1926-1927; 1927: 23-24). Estos versos compuestos por el obrero Américo Iglesias fueron "graciosamente interpretados por las obreras, vestidas con indumentarias originales" (LPA y CCS, 1926-1927; 1927: 23), formando un "cuadro vivo" en la entrega de premios de Bagley, en diciembre de 1926. Su transcripción, en cuatro páginas de la Memoria, fue acompañada por elocuentes fotografías (Foto 1). En el centro de la imagen una obrera vestía un elaborado disfraz de botella del licor Hesperidina, famoso producto de la casa, enmarcada por dos jovencitas graciosamente sentadas con sombreros en forma de galletitas. A la izquierda, una obrera estaba disfrazada de dulce de naranjas. Las restantes llevaban en la cabeza distintas variedades de galletitas, y en la placa central se leía el año de fundación de la fábrica (1864) y al año en curso. 


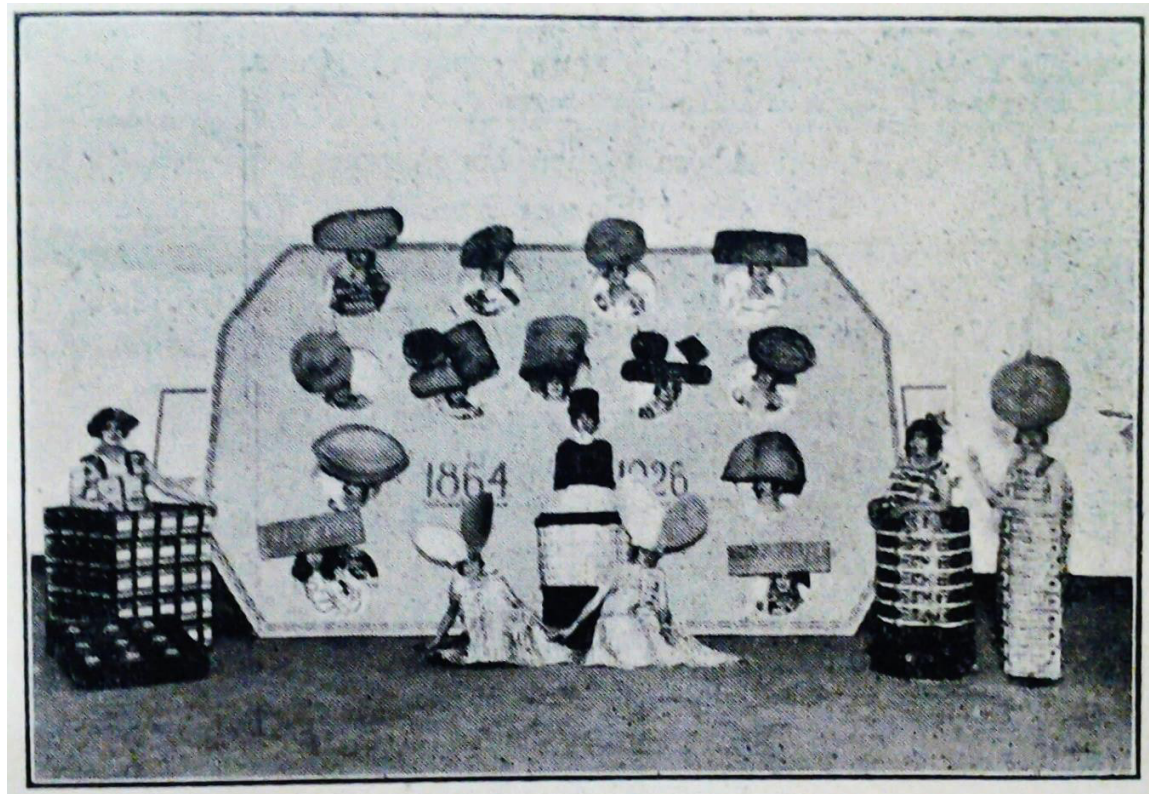

Foto 1: "Cuadro "Girls Biscuit Industria Nacional” por las alumnas obreras da la Escuela Bagley", LPA, CCS, op. cit., 1926-1927, p. 23.

Los cuadros vivos fueron un despliegue habitual en los actos de cierre de cursos. Sin embargo, ese año fueron un verdadero suceso. El gran escenario, los encendidos discursos, los esmerados trajes y los versos quedaron plasmados en la Memoria. Las obreras, disfrazadas en homenaje a los productos de la fábrica, los interpretaron recitando versos en primera persona y cerraron al unísono: "Viva la Casa Bagley/ y la Comisión Directiva." (LPA y CCS, 1926-1927; 1927: 26). Esta última se hallaba presente y debió estar muy complacida con los resultados del dinero invertido en la escuela. Si algo mostraban los discursos, los versos y la puesta en escena, era el éxito y el beneficio que representaba para el mantenimiento del orden y la conciliación en la fábrica, contrastando fuertemente con la participación femenina en las huelgas al comienzo de la década. El poema era una oda a la patronal, que buscaba generar una identificación profunda entre las obreras y los productos de su trabajo: las trabajadoras personificaron los productos, se vistieron y hablaron como ellos, transmitiendo el orgullo "patriótico" por la calidad de la producción industrial nacional y por el éxito entre el público (LPA y CCS, 1926-1927; 1927: 25). El enfático discurso de la obrera Auria Pérez así lo demostraba y los gerentes y directores debían sentirse orgullosos y complacidos con las palabras de agradecimiento finales, dirigidas a ellos: "Quiero, para terminar, pedirles a Uds., tanto a los miembros de las Comisiones de la Liga, como a los Señores Directores de la fábrica, [...] por cuanto los consideramos de nuestra misma familia, a quienes estamos sinceramente agradecidas" (LPA y CCS, 1926-1927; 1927: 21-2).

"Nuestra misma familia": ¿éxito del paternalismo industrial? En buena medida así lo fue durante estos años. En aquellas fábricas que empleaban gran cantidad de mujeres, donde el apoyo patronal fue más decidido, las escuelas habían logrado afianzarse y operaban como espacio de concordia entre obreras y patrones, bloqueando, al menos entre las asistentes, el desarrollo de "ideas extremistas" y la afiliación política y sindical. Si bien ningún obrero u obrera con vínculos sindicales y políticos de izquierda hubiera aceptado participar de estas alabanzas patronales, es posible que el reclutamiento liguista se hubiera operado entre aquellas más distantes al sindicato.

Sin embargo, este "éxito" no debe sobredimensionarse, ya que la oposición del movimiento obrero se hizo sentir. En 1921 una prolongada huelga en la fábrica de cigarros 
Avanti, donde trabajaban más de 1200 mujeres, puso de manifiesto la oposición de las obreras a la escuela liguista instalada allí. El conflicto se inició en 1920 por el intento de la fábrica de contratar operarias contrarias a la sociedad gremial, violando un acuerdo obtenido en una huelga anterior. El gremio manifestó su oposición, y la empresa respondió con un lock-out instigado por la LPA y la Asociación del Trabajo "ajeno" (como la llamaban anarquistas y socialistas). Las obreras y la Sociedad General de Obreros en Tabaco replicaron con la huelga y el boicot (N.N, 1921). La empresa contrató obreras no sindicalizadas como rompehuelgas e instaló la escuela para obreras de la Liga cuyo objetivo era, según denuncias socialistas, "enseñar a las crumiras [...] que habrán de aprender [...)] (a ser]) condiscípulas de los negreros de la liga patriótica, a las que por enseñarles ese arte se les cobra una buena cuota mensual que de seguro será para alimentar a esos vampiros acostumbrados a vivir en la holgazanería y a romper los movimientos huelguistas" (N.N, 1922). Eran evidentes el carácter pro-patronal de la escuela y la misión de la LPA de formar obreras dóciles, rompehuelgas y contrarias a la organización obrera independiente. Según la misma crónica, la escuela había "fracasado ruidosamente" (N.N, 1922), pero finalizada la huelga logró reconstruirse, siendo en 1922 una de las más grandes, con cinco profesoras y 250 alumnas. Para el éxito de la escuela, sin embargo, fue necesario derrotar al movimiento huelguístico. En 1926, Carlés relataba otra huelga en Dell'Acqua que había logrado gracias a la "propaganda hostil" el cierre temporal de la escuela. Aunque según Carlés las obreras habían renunciado al taller y al sindicato en forma de protesta por el cierre de la escuela (LPA y CCA, 1927; 1927: 39-40), esto parece dudoso, porque en 1927-1928 las Memorias ya no la mencionaban, indicando su pérdida de importancia, declive o cierre.

La escuela en Dell'Acqua no fue la única en desaparecer de las Memorias. Y si bien el número total de fábricas había aumentado con los años sostenidamente, sólo unas pocas merecían el nombre de "escuelas". Muchas no sobrepasaban un mero curso de alfabetización. La cantidad de obreras asistentes había crecido, pero en promedio las alumnas asistían sólo a un curso por semana. El adoctrinamiento que podía esperarse de una clase semanal de primeras letras, cálculo o costura era más bien bajo, aunque puede que la labor educativa diera a la LPA y las gerencias cierto prestigio entre las obreras.

En la asistencia masiva a los actos patrióticos pueden ponderarse ciertos aspectos de la adhesión femenina. Para el 9 de julio de 1926 los liguistas organizaron en plaza San Martín un desfile en el que las obreras ocuparon un lugar destacado y los gerentes decretaron feriado en las fábricas para que concurrieran. La columna principal estaba encabezada por la CCS, Carlés y dirigentes de la LPA, directores y gerentes de las fábricas y maestras. Las Señoritas y las obreras llevaban tules celestes y blancos en la cabeza, formando una gran bandera nacional (LPA y CCS, 1926-1927; 1927: 9-10). La LPA decía haber contratado cincuenta ómnibus para transportar a las obreras, un número impresionante. La adhesión femenina parecía ser la gran conquista de la Liga y el lugar preeminente de las obreras en la movilización lo ponía de relieve. Otros datos indican también la masividad de estas iniciativas. En Dell'Acqua, el mismo año de la huelga, habían asistido al acto de entrega de premios mil obreras, según números de la LPA (LPA y CCS, 1926; 1927: 34), sin duda abultados,aun así, impresionantes; aunque luego la escuela desapareció de las Memorias. ¿Era la asistencia voluntaria? ¿O aprovechaban las obreras la licencia otorgada por la patronal para evadir sus tareas laborales?

Un episodio pone en duda la voluntariedad y el entusiasmo de la asistencia. En 1925, un cronista de La Protesta informaba que las trabajadoras de la fábrica Gratry eran "poco afectas a la escuela 'liguista" instalada allí a efectos de embrutecerlas y mejor explotarlas. [El patrón] Las amenaza con el traslado a otro antro de explotación si 
6 La mayoría de las asistentes eran analfabetas.

7 Las escogidas para hablar eran "alumnas que se hicieron acreedoras por su comportamiento y aplicación": las que representaban y defendían los valores de la LPA. las mismas persisten en coronar sus "esfuerzos" con su ausencia o indiferencia". La asistencia, en este caso, parecía deberse a la amenaza y la presión patronal. El cronista luego llamó a las obreras: "Compañeras, [...] creemos que entre vosotras no existen esas mansas ovejas que a estas horas estarán balando y llorando a moco tendido por las consecuencias de semejante 'joya' carlesiana, pues demasiado sabéis vosotras, que ni con Cristos ni rosarios os librareis del yugo que os aniquila lentamente, [...] sino que vuestra emancipación debe buscarse empleando medios más eficaces..." (N.N, 1925). En sus palabras finales, el redactor concluía que la actitud de las obreras de Gratry era "alentadora" y "regocijante". Pero es factible deducir que semejante resistencia no debía ser la norma.

Anarquistas y socialistas criticaron las escuelas liguistas. Ambas fuerzas tenían en alta estima el valor de la educación y la cultura para el proyecto emancipatorio, y desde fines del siglo XIX impulsaron emprendimientos educativos entroncando con el movimiento pedagógico racionalista (Barrancos, 1990; 1991; 1996; 1997; Puiggrós, $1984 ; 1990)$. Por ello siguieron con preocupación el efecto "nocivo" de las escuelas de la LPA: la intencionalidad de éstas era explícita y fue plasmada en las Memorias y en los discursos de Carlés. Sin embargo, de cara a las obreras se afirmaba que la intención era educar "desinteresadamente" (LPA y CCS, 1924-1925; 1925: 16). Entonces, ¿por qué asistían las mujeres a estas escuelas? ¿por la presión de sus patrones? ¿porque eran "mansas ovejas"? ¿porque adherían al programa?

No es posible determinarlo con certeza ya que las voces de las obreras están mediadas por la prensa de derechas e izquierdas. Sin embargo, es posible realizar algunas conjeturas. En primer lugar, la razón principal de la asistencia era la alfabetización, de más utilidad y valor para las vidas cotidianas de las obreras que un programa completo de enseñanza, que insumía más tiempo y esfuerzo. Muchas obreras eran inmigrantes y analfabetas (LPA y CCS, 1927-1928; 1928: 23), ${ }^{6}$ y su asistencia solía reducirse a una clase semanal de alfabetización, cálculo básico o costura. Ahora bien, la oferta educativa pública para adultos se había ampliado en 1920 (Barrancos, 1990: 315). ¿Por qué preferían las obreras escolarizarse en su propio lugar de trabajo, y específicamente, en las escuelas de la LPA? Sin dudas que "educarse e instruirse en el mismo local", "sin incomodidad, ni pérdida de tiempo" era un factor (LPA y CCS, 1922: 4). Pero no debía ser el único, ni el determinante, ya que ningún obrero militante hubiera optado por ellas, prefiriendo las escuelas "libres" o "modelo". Posiblemente la asistencia sirviera también para ganar las simpatías de gerentes y directores, abriendo la posibilidad de ascensos; o para conservar el empleo. La sociabilidad y la posibilidad de asistir con amigas y compañeras del trabajo debían ser estimulantes.

Los discursos de agradecimiento en los actos de cierre de cursos, donde se destacan las voces de las obreras, no son ideales para ponderar la adhesión porque eran lugares de enunciación tutelados. ${ }^{7}$ Sin embargo, hay un discurso particularmente llamativo por la densidad cristiana militante. Su estilo descarnado y sincero pone en palabras lo que el resto de los discursos omite. En la distribución de premios a las alumnas de la escuela de Alpargatas, a fines de 1926, la obrera María Paz García dio lectura a su discurso en un tono de combate, aunque agradeciendo a la labor de la LPA:

...introduciendo la luz de la caridad cristiana en la tenebrosidad de las ideas ácratas [...] llevando en sus ensangrentadas manos el estandarte de la salvación social y las ideas Dios Patria, Familia, Honor [...]. Nosotras desheredadas de la fortuna [...], hemos encontrado en la Liga Patriótica el ancla de salvación en el proceloso mar de la lucha de ideas. Ganamos el pan nuestro de cada día al amparo del Divino Obrero Jesús: de sus discípulos los cristianos recibimos nosotras las obreras instrucción gratuita, si enfermamos nos curan en un hospital fundado por cristianos, nos cuidan cristianas mujeres muchas de ellas antes millonarias 
o de noblísimas familias o de grande instrucción y las fábricas mismas que nos proporcionan trabajo son propiedad de cristianos. En una palabra: no del Anarquismo ni del Socialismo recibimos el bien comparable al que recibimos del seno de la religión cristiana y si no decidnos: ¿Qué hospitales, que asilos, que hermanas enfermeras, que caridades, que alimentos fundó el Socialismo o Anarquismo? (LPA y CCS, 1926-1927; 1927: 27-28).

Primaba en la ponderación de la obrera una, afiebrada católica, una concepción utilitaria. Poniendo en la balanza lo que una y otras fuerzas tenían para ofrecer, ganaba la LPA: instrucción gratuita, atención médica, empleo. Era el cristianismo obrerista el que realizaba las mayores obras en favor de las trabajadoras. Si bien no es posible generalizar a partir de este testimonio, sí parece factible que para muchas obreras distantes del anarquismo, el socialismo o el sindicalismo, las escuelas fueran una opción práctica de la que podían sacar cierto provecho y conocimientos útiles a sus intereses, asistiendo una vez por semana dos horas. Acostumbradas al trabajo en las fábricas, tampoco debe haberles resultado demasiado rígida la disciplina. Y si se tornaba muy agobiante, siempre podían dejar de asistir: en teoría, nada las obligaba. No debe sobreestimarse tampoco el nivel de adhesión y adoctrinamiento logrado. Si bien los actos mostraban una importante participación, la Liga había logrado que las obreras tuvieran franco, y las transportaba hasta allí. Probablemente muchas prefirieran participar y evadir la agotadora jornada laboral, aunque en ocasiones se resistieron y fueron presionadas por sus patrones, y hubo escuelas que fracasaron.

El balance es por lo tanto ambivalente. La mayoría de las escuelas prosperaron. Sin dudas las obreras que asistieron no eran activistas de sus gremios, y anarquistas y socialistas tenían posiciones muy críticas a la LPA. Pero esto no las convertía tampoco en adherentes de la Liga. Sin embargo, probablemente las alejara de la militancia sindical y política, contribuyendo a fomentar en ellas lo "propiamente femenino": el hogar, las labores, la crianza de los hijos. La propuesta liguista tenía un atractivo extra: a diferencia de la militancia de izquierda, no involucraba riesgos con los patrones, ni conflictos con los valores tradicionales. Lejos de implicar una ruptura con la ideología maternal estatal y socialmente dominante, se montaba sobre esta y la reforzaba. Solo excepcionalmente podía traer roces con los varones militantes en las fábricas.

Por otro lado, el movimiento obrero por esos años tuvo una posición ambigua frente a la participación femenina. Si bien no hubo posturas únicas, hubo voces como la que cita Mirta Lobato de La Protesta (22/03/1919): “Todas las mujeres no pueden ser Luisa Michel, la señora Severine, Emma Goldman o Rosa Luxemburgo. Estas heroínas de las reivindicaciones proletarias son excepciones raras. ¡Si todas las hembras desearan obrar como ellas exactamente, se acabarían en el mundo las novias y las madres! [...] La mujer fuera del hogar [...] representa un obstáculo serio" (Lobato, 2000: 102-103).

En este punto, el mensaje de Carlés era más atrayente, adulaba a las obreras y les daba un sentido de pertenencia, una labor, y una misión de vida y en el porvenir de la patria. Las incluía, las interpelaba como grupo y las valoraba positivamente en sus roles tradicionales. De allí que, donde los cursos de la Liga lograron plasmarse en verdaderas escuelas, como es el caso de Bagley, pueda afirmarse sin dudas que fueron exitosas y lograron su cometido.

\section{Recapitulando: "una selva de aplausos"}

Fuerzas contrarias y conflictos de clases atravesaron los espacios laborales en el periodo de posguerra. Sus formas más evidentes, que han atraído mayor atención, 
han sido los momentos de extrema conflictividad como las huelgas. Sin embargo, pasado el ascenso huelguístico llegaba la hora de recoger los frutos, y a ello se dispusieron las organizaciones obreras; pero también las patronales y las organizaciones de derechas, que parecían las grandes vencedoras del periodo, aunque su éxito entre los obreros varones fue limitado.

Las escuelas de las que nos hemos ocupado aquí se establecieron en grandes fábricas donde el elemento femenino tenía un peso decisivo, algunas de ellas grandes fábricas donde las izquierdas no pudieron, o sólo de forma marginal, hacer pie. Si bien en ciertas fábricas la Liga no fue exitosa, sí logró afianzarse y constituir verdaderas escuelas en algunas de las más importantes: Bagley, Noel, Alpargatas, Gratry, Bunge y Born y Piccardo, entre otras.

Más allá de que dijeran a las obreras que el objeto de estas era educar "desinteresadamente", la finalidad de las escuelas era más adoctrinadora que formativa. Los conocimientos que se enseñaban no apuntaban a la formación en oficios ni a impartir conocimientos útiles al trabajo fabril, sino más bien a moralizar, maternalizar y evangelizar. Los objetivos eran políticos y se centraban en la construcción de la disciplina laboral en las fábricas y en el mantenimiento del orden, buscando alejar a las obreras de ideologías como el anarquismo o el socialismo. Para ello la ideología maternal y el catolicismo fueron soportes centrales. Si bien la adhesión profunda y genuina de las obreras no puede determinarse y primó una participación utilitaria, es factible suponer que la influencia de la Liga en las escuelas que llegaron a ser exitosas logró bloquear o dificultar, en un período de reflujo y descenso de la conflictividad laboral, el desarrollo de las izquierdas. Así pues, no vemos a derechas e izquierdas actuar en el vacío. Y el interés por el reclutamiento femenino, desdeñado en ocasiones por el movimiento obrero, fue en cambio la piedra de toque del relativo éxito liguista en 1920. 


\section{Q Bibliografía}

»Auza, Néstor T. (1987). Aciertos y fracasos sociales del catolicismo argentino: realizaciones y conflictos. Mons. de Andrea, Vol 2, Buenos Aires, Docencia/Don Bosco.

" Badaloni, Laura Irene (2007). “Prácticas paternalistas. Sus alcances y límites en el disciplinamiento y control de la mano de obra: el caso del Ferrocarril Central Argentino durante las primeras décadas del siglo XX en Rosario y alrededores", Anuario IEHS, №22, pp. 507-24.

"Barbero, María Inés, y Ceva, Mariela (1997). "El catolicismo social como estrategia empresarial. El caso de Algodonera Flandria (1924-1955)", Anuario IEHS, $\mathrm{N}^{\circ} 12$, pp. 269-289.

"Barrancos, Dora (1990). Anarquismo, educación y costumbres en la Argentina de principios de siglo, Buenos Aires, Contrapunto.

»- (1991). Educación, cultura y trabajadores (1890-1930), Buenos Aires., CEAL.

»- (1996). La escena iluminada: ciencias para trabajadores, 1890-1930, Buenos Aires, Plus Ultra.

》- (1997). “Socialistas y suplementación de la educación pública: la Asociación de Bibliotecas y Recreos Infantiles (1913-1930)", en Morgade, Graciela (Comp.), Mujeres en la educación: género y docencia en la Argentina, 1870-1930, Buenos Aires, Miño y Dávila., pp. 130-150.

» Bilsky, Edgardo J (1984). La Semana Trágica, Buenos Aires, CEAL.

"Carlés, Manuel (1921). "Discurso pronunciado en el acto de clausura de los cursos de la Primera Escuela Gratuita de la Brigada `17 de Señoras" en Acción civilizadora de las escuelas de la LPA, Buenos Aires, Biblioteca de la LPA.

"Carlés, Manuel, Liga Patriótica Argentina \& Comisión Central de Señoritas (1922). Sus escuelas de obreras en las fábricas, Buenos Aires, Biblioteca de la LPA.

"Caruso, Laura (2012). Los trabajadores marítimos del Puerto de Buenos Aires: condiciones laborales, organización sindical y cultura política, 1890-1920, tesis de Doctorado en Historia, Facultad de Filosofía y Letras, Universidad de Buenos Aires.

»Caterina, Luis María (1995). La Liga Patriótica Argentina: un grupo de presión frente a las convulsiones sociales de la década del veinte, Buenos Aires Corregidor.

"Ceva, Mariela (2010). Empresas, trabajo e inmigración en la Argentina: los casos de la Fábrica Argentina de Alpargatas y la Algodonera Flandria, 1887-1955, Buenos Aires, Biblos.

"Devoto, Fernando (2002). Nacionalismo, fascismo y tradicionalismo en la Argentina moderna, Buenos Aires, Siglo XXI.

》Dicósimo, Daniel Oscar (2008). “La oposición de los trabajadores al disciplinamiento productivo durante la última dictadura militar. Una reflexión conceptual”, Revista Paginas, 2010, vol. 1, no 1, p. 51-67. pp. 51-67. 
» Godio, Julio (1972). La semana trágica de enero de 1919, Buenos Aires, Hyspamerica.

»Lida, Miranda (2013). Monseñor Miguel de Andrea (1877-1960), obispo y hombre de mundo, Buenos Aires, Edhasa.

»__ (2012). "Iglesia, Sociedad y Estado en el pensamiento de monseñor Franceschi. De la seditio tomista a la 'Revolución Cristiana' (1930-1943)”, Anuario del IEHS, № 17, pp. 109- 124.

» Liga Patriótica Argentina (1919). Estatutos, Buenos Aires, Biblioteca de la LPA.

»Liga Patriótica Argentina y Comisión Central de Señoritas ([s/f]1922; 1924; 1925; 1926; 1927; 1928). Memoria de 10 escuelas obreras, Buenos Aires, Biblioteca de la LPA.

»- $([\mathrm{s} / \mathrm{f}] 1926 ; 1927)$. Memoria de las escuelas gratuitas obreras, Buenos Aires, Biblioteca de la LPA.

"Lobato, Mirta Zaida (2000). "Lenguaje laboral y de género en el trabajo industrial. Primera mitad del siglo XX”, Gil Lozano, Fernanda, Ini, María Gabriela y Pita, Valeria Silvina (Eds.), Historia de las mujeres en la Argentina. t. II. Siglo XX., Buenos Aires, Taurus.

》___ (2001). La vida en las fábricas: trabajo, protesta y política en una comunidad obrera, Berisso (1904-1970), Buenos Aires, Prometeo.

》- (2007). Historia de las trabajadoras en la Argentina (1869-1960), Buenos Aires, Edhasa.

»Lupano, María Marta (2009). La gran familia industrial: espacio urbano, prácticas sociales e ideología, 1870-1945, Buenos Aires, Santiago Arcos.

"Lvovich, Daniel (2003). Nacionalismo y antisemitismo en la Argentina, Buenos Aires, Javier Vergara, Grupo Zeta.

» McGee Deutsch, Sandra (2003). Contrarrevolución en la Argentina 1900-1932: la Liga Patriótica Argentina, Buenos Aires,UNQ.

”- (2005). “Contra 'el gran desorden sexual': Los nacionalistas y la sexualidad, 1919-1940”, Cuadernos del CISH, N 17-18, pp. 127-150.

»Neiburg, Federico (1988). Fábrica y villa obrera: historia social y antropología de los obreros del cemento, Buenos Aires, CEAL.

» N.N (1919). “Carlés y las “damas”, La Protesta, Buenos Aires, 29 de octubre de 1919.

» N.N (1921). "La huelga en la casa 'Avanti'. La activa e inteligente participación de la mujer”, La Vanguardia, enero.

"N.N (1921). "S. General de obreros en tabaco. La huelga de la casa Avanti. Fracaso de la escuela interna", La Vanguardia, Buenos Aires, 3 de enero de 1921.

" N.N (1922), Boletín de servicios de la Asociación del Trabajo, Año III, n57, Buenos Aires, 5 de junio de 1922, pp. 227-228.

" N.N (1925), "Manolo y las obreras", La Protesta, Buenos Aires, 24 de noviembre de 1925 .

» Ospital, María Silvia (1994). Inmigración y nacionalismo: la Liga Patriótica y la Asociación del Trabajo (1910-1930), Buenos Aires, CEAL.

» Puiggrós, Adriana (1984). La educación popular en América Latina, México, Nueva Imagen. 
- (1990). Sujetos, disciplina y curriculum en los orígenes del sistema educativo argentino, Buenos Aires. Galerna.

"Queirolo, Graciela (2008). “El mundo de las empleadas administrativas: Perfiles laborales y carreras individuales (Buenos Aires, 1920-1940)", Trabajos y Comunicaciones, Departamento de Historia, Facultad de Humanidades y Ciencias de la Educación, Universidad Nacional de La Plata, N 34, pp. 129-151.

"- (2010). "Las mujeres y los niños en el mercado de trabajo urbano (Buenos Aires, 1890-1940)", Recalde, Héctor (Ed.), Señoras, universitarias y mujeres (1910-2010): la cuestión femenina entre el centenario y el bicentenario de la revolución de Mayo, Buenos Aires, Grupo Editor Universitario.

»Rapalo, María Ester (2012). Patrones y obreros: la ofensiva de la clase propietaria, 1918-1930, Buenos Aires, Siglo XXI.

"Rocchi, Fernando (2000a). “Concentración de capital, concentración de mujeres industria y trabajo femenino en Buenos Aires, 1890-1930", Gil Lozano, Fernanda, Ini, María Gabriela y Pita, Valeria Silvina (Dirs.), Historia de las mujeres en la Argentina. t. II. Siglo XX., Buenos Aires, Taurus.

»__ (200ob). “Un largo camino a casa: empresarios, trabajadores e identidad industrial en Argentina, 1880-1930”, Suriano, Juan (Ed.), La cuestión social en Argentina, 1870-1943, Buenos Aires, La Colmena.

» Rock, David (1977). El radicalismo argentino, 1890-1930, Buenos Aires, Amorrortu.

»Rubinzal, Mariela (2012). El nacionalismo frente a la cuestión social en Argentina (1930-1943): Discursos, Representaciones y prácticas de las derechas sobre el mundo del trabajo, tesis de Doctorado, Universidad Nacional de la Plata.

» Scheinkman, Ludmila (2014). “Estrategias patronales de organización y gestión del trabajo y la producción en las fábricas de dulces, chocolates y galletitas de la Ciudad de Buenos Aires (1880-1930)", Marcelo Rougier (Ed.), Perspectivas sobre la industria: Documento de Trabajo 1, Buenos Aires, FCE, Universidad de Buenos Aires.

» Simonassi, Silvia Graciela (2007). “Conflictividad laboral y políticas disciplinarias en la industria metalúrgica de la ciudad de Rosario 1973-1976, Anuario IEHS, №22, pp. 465-86.

»Zanatta, Loris (1996). Del Estado liberal a la Nación Católica. Iglesia y Ejército en los orígenes del Peronismo, 1930-1943, Buenos Aires., Universidad Nacional de Quilmes. 
